\title{
SOA BASED INTEGRATION INFORMATION SERVICE PLATFORM STRATEGY IN RURAL INFORMATIZATION
}

\author{
Baoqing Dong ${ }^{1, *}$, Lei Chen ${ }^{2}$, Yuefeng Zhou ${ }^{3}$ \\ ${ }^{1}$ School of Geoscience and Space Science, Peking University, Beijing, 100871 P. R. China \\ ${ }^{2}$ Network \& Information Center of Liaoning University, Shenyang, 110036, P.R.CHina \\ ${ }^{3}$ College of Economics and Management, Dalian University, P.R.China \\ * Corresponding author, Address: School of Geoscience and Space Science, Peking \\ University, Beijing 100871,P.R. China, email:qingbd@263.net
}

Abstract: This paper compares the hierarchical structure between SOA and integration information service platform in rural informatization, analyse the main problems in the macro level of rural information and gives some strategy advices in service-oriented integration information service platform on rural informatization. Through the implementation of pilot projects, it is proved that the SOA architecture has good effect in the rural information resources integration.

Keywords: SOA, Rural informatization, related agriculture information platform, integration

\section{INTRODUTION}

With the development of information technology and government function reform, the demand in rural informatization is increasing. It involves multiple sectors and industries. Each sector builds their own business syetem in accordance with their needs. However, These business systems base on different technical standards, different software and hardware platforms, and these heterogeneous systems are developed by different software providers. The status of information island has been formed

Please use the following format when citing this chapter:

Dong, B., Chen, L. and Zhou, Y., 2009, in IFIP International Federation for Information Processing, Volume 295, Computer and Computing Technologies in Agriculture II, Volume 3, eds. D. Li, Z. Chunjiang, (Boston: Springer), pp. 1919-1927. 
In order to achieve high efficiency, low cost of promoting the rural information and intensive construction and resource integration has become an important initiative. To this end, government departments must be resolved between the integration of information systems integration. Webbased services of a service-oriented architecture, to achieve heterogeneous platform for information integration, inter-governmental support within and across sectors and between the end-to-end integrated services through the newly-formed new services, agriculture and the rural information Integrated agriculture-related information service platform to consider the top-level design provide a new opportunity.

\section{SOA ARCHITECTURE AND THE KEY TECHNOLOGY}

\subsection{SOA architecture}

SOA is a coarse-grained, loosely coupled, platform-independent and programming language, standards-based software architecture model, as shown in Figure 1.

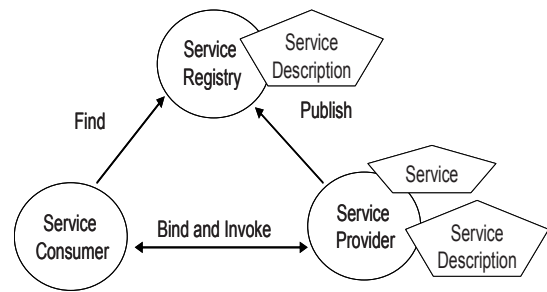

(a)

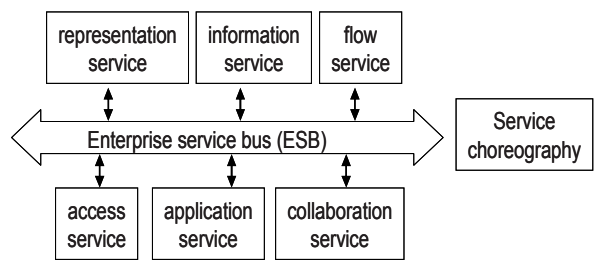

(b)

(1)Service provider:

Fig. 1: SOA basic structure

An agent that can be addressed through a network, Its acceptance and implementation of the request from the users. It will own services and interface services contract issued to the registration centers, so that users can find and access the service.

(2)Service consumer:

An application or a software module or the need for a service of another service, which launched the registration centre in the services available through the transmission bundled services, and implementation of services in accordance with the user interface services contract to perform the services.

(3)Service registry: 
Services find that supporters. It includes a repository of available services, and allows users to find services of interest to service providers interface information.

Service-oriented architecture of each entity is playing a service provider, the user registration centre and three in a certain role in one or more.

\subsection{Functional properties based on SOA}

SOA is a style of architecture, it features the application of the different units - services, through service between the definition of a good interface and contract linked. Interface defined by a neutral, independent of the concrete realization of the hardware platforms, operating systems and programming languages, making construction of the system of services can use the unified and standard approach to communications. Such a neutral definition of the characteristics of the interface between loosely coupled services called.

In the SOA model, all the business logic are in the form of packaging services, they can be shared, reuse and configuration. An application is composed by any number of services component, which is through the Enterprise Service Bus (ESB) for communication, interaction and presentation management. Each service through the standard interface can be invoked by other services. Each application by the service providers, consumers and service agent component, which is in a standard form of interactive services complete business functions. Its interactive relationship is shown in Figure 1(a).

SOA model of thinking to achieve service-oriented application to unity and a common way of interactive service, can be easily achieved between the business applications of data integration, application integration, business integration.

\subsection{Operation of SOA}

SOA realization of the entire service is the core. SOA is an essential element of services, SOA designated a group of entities (service providers, consumers, service registry, the terms of service, service agents and service contract), these entities a detailed description of how to provide and receive services. These services are interoperable, independent, modular, location specific, the loosely coupled through the Internet and can find their address.

Service-oriented architecture in the operation include the following three points.

Publish: In order to make services accessible, the need to issue service description to enable service users can find it. 
Find: Service to those requesting it location-based services, it is for the registry to find services to fit their standards of service.

Bind and invoke: To describe the search service, the service users continue to service description information to call services.

\section{SOA BASED INTEGRATION DESIGN IN RURAL INFORMATION SERVICE}

\subsection{The overall framework of integration information service platform in rural informatization}

The rural information integrated information service platform for the general overall structure of the "five horizontal two longitudinal.

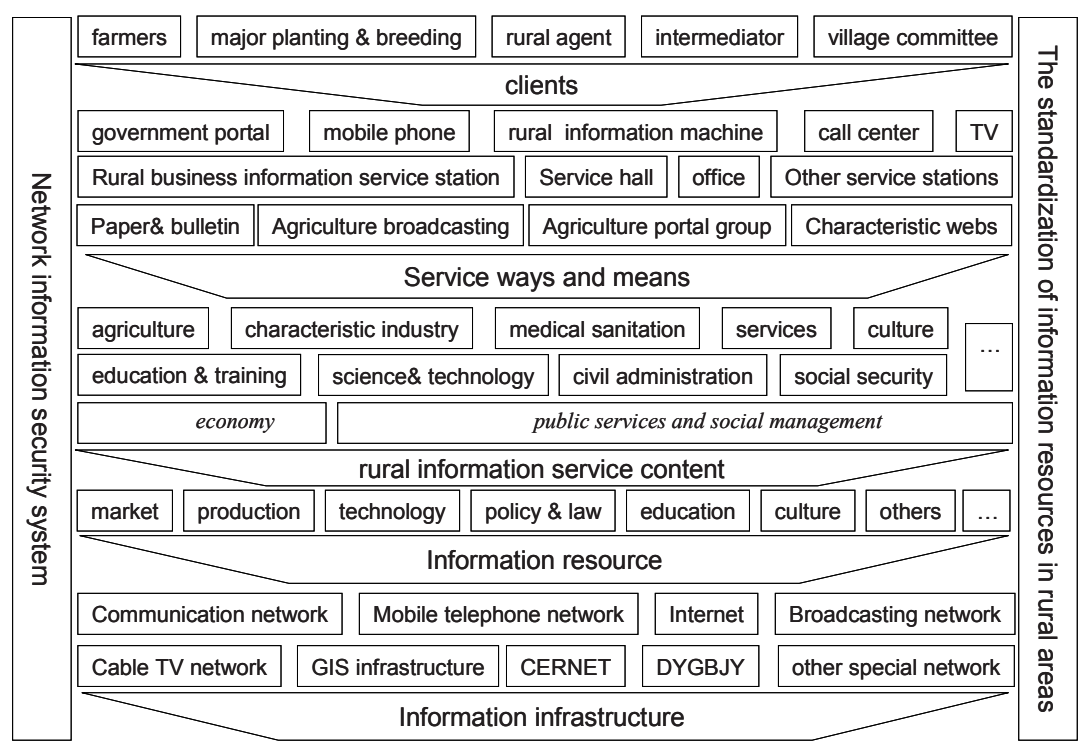

Fig 2: The overall framework of related agriculture information platform

'Five horizontal' refers to the information infrastructure, information resources, services, channels and service establishments, service targets. 'Two vertical' refers to the rural areas of standardization system of information resources and information network security system.

The platform in the field of information technology in generally refers to all kinds of resources and services to the exchange, integration and operation of a hardware and software environment. Agriculture-related information service platform is the exact meaning of the entire information technology 
work in rural areas involved in a variety of technical means, a variety of methods of work, organizational structure and sharing of data transmission, such as the form of a standardized definition, as the internal integration of business support, The total external environment to provide services in this environment, including all the services.

From the rural areas of the information building to the actual situation analysis, integrated information service platform external interface is a classic example of the portal, agriculture-related portal sites and call centers, including on the agriculture-related portal in Internet, the Government of the agriculture-related portal in special network, also include support them operation, the network, computer hardware and software system, security measures, information resources and service teams, service establishments (access points), services content, and so on.

\subsection{The demand of Agriculture-related information service platform}

1) Basic requirement of integration

Platform moves up, service moves down. It is better to promote the deployment of agriculture-related information service platform in high-level administrative region, and intensive construction in province or city or county. It isn't necessary to establish agriculture-related information service platform in the region of below county. And the agriculture-related information service platform can be directly established in province if there is no condition in city level.

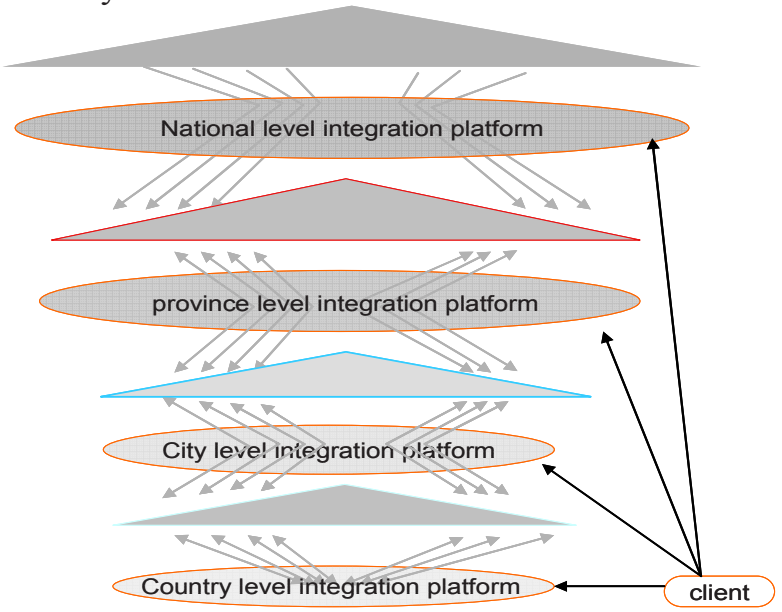

Fig 3: The integration of agriculture-related information service platform

2) One network carries variety of business 
The net resources share in rural region should be promoted suitably. And the department of telecommunication, broadcast and television should be encouraged to display their respective advantages by government, which can promote a variety of terminal services business and business integration. At the juncture of speeding up agricultural and rural information construction, removing institutional obstacles and exploring the rural areas "Sanwangronghe" mechanism should be promoted. Regardless of which kind of network formed in the past, under quality assurance, it is necessary to develop a variety of services by way of IPTV and cable Internet

3) Many purposes based on one terminal

Relying on fixed communications, mobile communication, Internet portals, radio, television and newspapers, books, columns and other publicity channels of information dissemination, information services and applications can be promoted into villages and peasant households.

\subsection{The technologies design of platform integration}

Compared with the traditional integration method, SOA-based integration has more advantages, such as reused, platform-independent, standards-based, coarse-grained, loosely coupled, and change according to business needs, and so on. In addition, SOA structure itself has a good scalability, flexibility and adaptability, and it is easy to achieve interoperability and information share among applications, and to avoid "isolated island" among the applications of information systems. Therefore, it is a better choice to use SOA framework to establish rural synthetical information service platform. The structure is shown in Figure 4.

In this structure, unified application platform is composed of supporting software, infrastructure, application service framework. The difference from other application supporting platform is that this platform encapsulates every functional component by forms of service, which form into enterprise service bus (ESB) to carry out standard service of interoperation and information exchange. Services based on standards become the knot of application. Through the ESB the interoperability between different services can be achieved, and the scheduling and combination of services increase the flexibility, reusability and integration, which provide flexible and convenient method for application and business process to access into. 


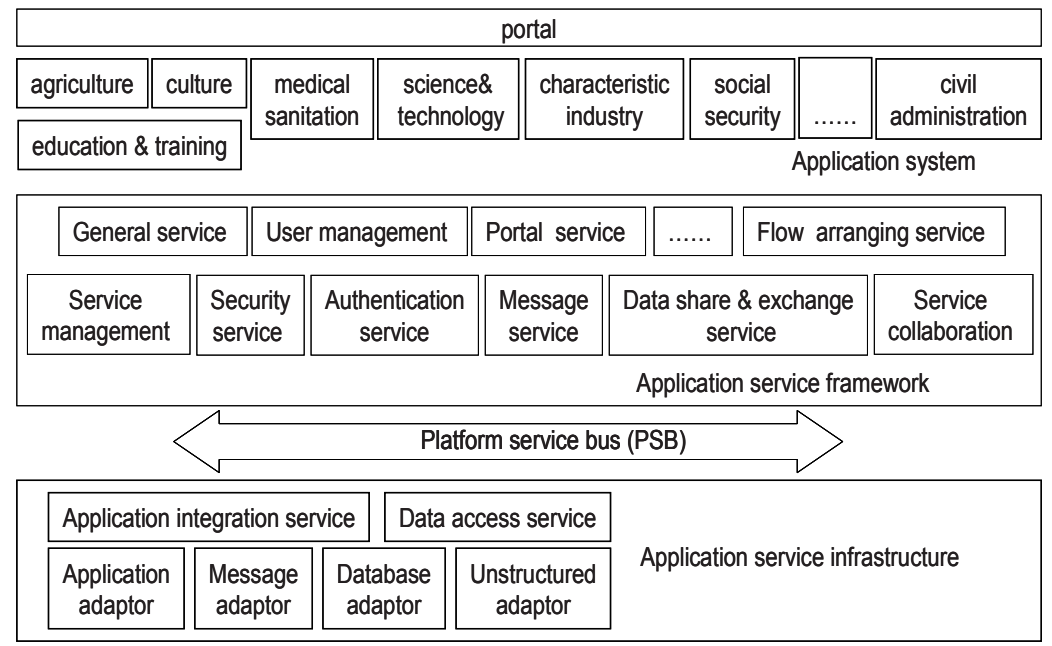

\begin{tabular}{|c|c|c|c|c|}
\hline \multicolumn{5}{|c|}{ Uniform application platform of support } \\
\hline Application server & Portal server & Web server & Suppor & \\
\hline Database & EIS & $\mathrm{XML}$ & WWW & Data resource \\
\hline
\end{tabular}

Fig 4: The technology structure of rural synthetical information service platform based on SOA

1) Basic infrastructure of application service.

It uses middleware to achieve interoperable, reusable infrastructure and services and to provide a service-oriented and application-oriented basic environment, and can shield difference of software platforms, all of which make the service platform to be cross-platform, cross-integration technology. Application service infrastructure is composed of enterprise service bus, service delivery channels and interactive environment.

2)Framework of application service

Framework of application service is the service set and service interface, which is acquired by abstracting common functions in specific field of agricultural-related synthetical information service platform, such as portals and user management, identity and some common service. SOA-based agricultural-related synthetical information service platform can quickly reflect to business change and provide new service application, because the application deployed on the SOA application supporting platform can easily reuse from application service platform and recompose basic service and common service, also can add new function and service.

3) Typical basic services. Include the following aspects.

a) Data access services.

b) Data share and exchange services.

c) Application and integration services. 
d) Collaborative business services.

e) Portal services.

f) Unified security services.

g) Unified management services.

\section{EXPERIMENT AND APPLICATION}

According to the design mentioned above, the Ningxia Hui Autonomous Region has been selected as a trial area to implement the fully integrated agriculture-related information resource. The SOA-based agriculture-related information service platform was built in Ningxia to integrate rural information resources, and has achieved better results, which are listed in the following.

1) The utilization of existing resources

Service-oriented structure can be developed based on existing investment system, without the need of a completely new system. By ways of appropriate SOA framework, business service can be constructed into component set, which can be used only if you know the name of interface, the internal details of service. The complexity of data transmission among components of the service is hidden from outside, which makes existing resources be used and can be packed by ways of service to be provide to new system or others to access.

2) Commercialisation of infrastructure

Utilization of SOA framework will make the development and deployment uniform between different application programs of government web. The components set, which are combined with existing components, new components and components bought from manufacturers in a defined framework, will be deployed on agricultural-related information service platform as service.

3) Costs cut

As the development of business demand and introduction of new demand, costs of strengthening present and new application programs and establishing new service can be reduced greatly by way of the SOA framework and services library.

\section{CONCLUSION}

Practice shows that there are more problems existing in agriculture, for example wide field, a variety of information source, information resources of agricultural and agricultural-related departments. And there is no uniform management system, which makes agricultural information to be owned by 
departments itself without share. And also there is no uniform standard for technologies to develop agricultural system leading to the lack of effective information integration tools. The utilization of loosely coupled SOA architecture in the integration of agriculture-related information systems resources can solve these problems mentioned above, which will achieve narrow the urban-rural digital gap by spending relatively less time and financial resources.

\section{REFERENCES}

CHAPPELL D. 2004. Enterprise service bus[M ]. Sebastopol, CA: O'Reilly Media, 2004.

Dreyfus P. 2006. "What's the best software to implement as a service if you're just starting SOA?" http://www-128.ibm.com/developerworks/library/ar-itio4/.

Gartner P.M. 2006. "Service-Oriented Architecture Craves Governance." http:// www.gartner.com/DisplayDocument?id=488180.

Gronmo R., Skogan D., Solheim I. 2004. Model-driven Web services development. In: Proc of the 2004 IEEE Int Conf on e-Technology, e-Commerce and e-Service (IEEE'04). Taipei.

IBM. 2005. Service2oriented architecture and Web services [ EB /OL ]. http: / /www. ibm.com/services/us/imc/html/soa.html.

Li Daoliang. 2007. Report of China's rural information development.

Newcomer E. Greg L. 2005. Understanding SOA with Web Services. Boston, MA: AddisonWesley.

PapazoglouM P. 2003. Service-oriented computing: concepts, characteristics and directions. In: Proc. Int Conf on Web Information Systems Engineering (WISE03). Los Alamitos. 2003: 3-12

Yefim V. N., Roy W. S. 2006. "Advanced SOA for Advanced Enterprise Projects." http://mediaproducts.gartner.com/reprints/oracle/141940.html. 